\title{
Switching Behaviour in Smart Phone Messaging Services - It's a Question of Context, Content, and Features of the Service
}

\author{
Brad McKenna \\ University of East Anglia \\ b.mckenna@uea.ac.uk
}

\author{
Petri Mäkinen \\ Sofigate \\ petri.makinen@sofigate.com
}

\author{
Tuure Tuunanen \\ University of Jyväskylä \\ tuure@tuunanen.fi
}

\begin{abstract}
This paper studies switching behaviour in smart phone messaging services. This study aims to add knowledge about the factors affecting switching behaviour in smart phone messaging services. The empirical study is qualitative, and the data was collected with interviews using the laddering method. This study was carried out to find out the reasons behind customer decisions when choosing between smart phone messaging services. Using the Push-Pull Mooring framework, the findings of this study indicate that the switching decision regarding smart phone messaging service is influenced by three factors: the context of the message, the content of the message, and the features of the service.
\end{abstract}

\section{Introduction}

Factors that lead consumers to switch products or services to other substitute alternatives have long been an area of interest for researchers [1]. The process by which the consumer switches from one service provider to another, or an alternative service provider, is called exchange behaviour [2]. The study of consumer switching is a valuable research topic, because understanding the factors leading to it is at the heart of long-term and loyal customer relationships [3].

Behavioural change in the context of digital services has been studied quite abundantly in recent years. Topics include, e.g., telecom operators [4, 5], community services $[6,7]$, and cloud-based healthcare services [8]. Han, et al. [9] suggest that research on digital service switching behaviour can generally be divided into three categories: 1) process models describing exchange behaviour; 2) analysis of the differences between 'changers' and 'keepers', and; 3) studies on the causes and factors influencing exchange behaviour.

Hsieh, et al. [10] used the Push-Pull-Mooring (PPM) framework to increase their understanding of the factors influencing exchange behaviour and their classification. They investigated blogging services, their features, and previous research on interchange behaviour, which factors could influence and explain the changing behaviour of blog services in the context. They explored the most important factors influencing blog interchange behaviour, and dividing those factors into push, pull and mooring factors according to the PPM framework. Later, $\mathrm{Xu}$, et al. [11] built their research model on exchange behaviour in community services in a similar way to Hsieh, et al. [10]. Thus, $\mathrm{Xu}$, et al. [11] used the PPM framework as the basis for their research model. In addition to this they explored what kind of factors can be seen to affect community service exchange behaviour.

By understanding switching behaviour and the underlying factors, it would be possible for a company to create as strong and long-lasting customer relationships as possible [3]. Consequently, the resulting long-lasting and mutually trusting customer relationships are very important for successful business [10]. Compared to non-loyal customers, it is easier to sell new products and services to loyal customers.

However, while switching behaviour has been extensively studied in the context of digital services, and digital services are increasingly being used for smart phone devices, studies of the changing behaviour in the context of smart phone services is sparse. Thus, our research question in the study is as follows: What factors affect consumer switching behaviour in the context of smart phone device messaging applications? We apply a qualitative research approach to study this and more specifically the interviewing laddering technique [12, $13]$ and thematic content analysis $[14,15]$.

Next, we review the PPM framework literature and thereafter depict our research methodology. This is followed by the findings, discussion of the implications of our study and conclude with some limitations of the study and possible future research topics.

\section{Consumer Switching Behaviour: PPM Framework}


The most widely used model in the field of research on the exchange behaviour of information systems in an attempt to explain consumer switching behaviour and the underlying factors is the PPM framework [16]. PPM was originally developed to explain the causes of human migration and migration behaviour. Thus, the reference framework was intended to explain why people move from one place to another within a particular time [1]. The roots of this framework date back to the $1885 \mathrm{~s}$ when the Laws of Migration [17] were presented. Since then, researchers of migration behaviour have used this work in numerous studies $[10,18]$. The PPM framework itself consists of three different categories, which can be divided into factors influencing the migration decision of the people and thus the migration behaviour. These factors are divided into push, pull, and mooring factors [19]. Since then, Bansal, et al. [1] have successfully used this reference framework in the context of service exchange behaviour research, since the underlying factors of migration and exchange of services appear to be similar.

The push factors are those factors that negatively affect the prevailing state and specifically encourage exchange because the current product or service is somehow unsatisfactory [16]. Bogue [20] suggests that, when people talk about migration, there are factors such as lack of jobs, low wage levels and natural disasters. Applying the PPM framework in the context of services, Bansal, et al. [1] suggested that the poor quality of the current service, poor value, low confidence, poor commitment, and high price are the push factors. Chuang and Tai [21], in turn, present their own literature review of service exchange behaviour, citing that the factors associated with the enjoyment of the current service are the most important pushing factors affecting switching behaviour.

Pulling factors are factors that increase the positive image of an alternative product or service. Thus, the pull factors encourage the exchange, precisely because the replacement of the current state seems to be attractive [16]. Bogue [20] suggests that, when talking about people's migration, there are, for example, better job opportunities, a better wage level and a more pleasant climate. Bansal, et al. [1], for their part, suggest that in the context of services, the pulling factors of the PPM framework are very much related to the attractiveness of the alternative. Chuang and Tai [21] are in the same line of proposing that the most important pull factors for switching behaviour in the context of services are specifically related to the attractiveness of the alternative service.

The mooring factors are factors that often do not in themselves cause exchange behaviour, but they can either promote or slow it down. The mooring factors often affect the switching behaviour by having either a positive or a negative effect on pushing or pulling factors $[11,19]$. In the context of human migration behaviour, such mooring factors include distances between places of residence and the cost of migration [17]. For example, in terms of service switching behaviour, mooring factors include a negative attitude towards service exchange, high switching costs caused by exchange, minor experience in switching services, and subjective standards [1]. Chuang and Tai [21] argue that factors relating specifically to the cost of exchange are the most crucial mooring factors in terms of switching behaviour in the context of services.

\section{Research Methodology}

\subsection{Laddering Interview Method}

A qualitative interviewing approach was used for this research. The laddering interview was chosen as the interview method. Tuunanen, et al. [22] suggest that laddering interviews can be used to identify and understand the factors that influence the use of digital services and their use. The laddering interview creates value chains consisting of attributes, consequences and values. By collecting these value chains from several interviewees, it is possible to create a unified network on the basis of these chains and to look at what interdependencies between different chains can be seen [12].

During a laddering interview it is intended that the interviewer will try to ask questions such as "why is this important to you?" Thus guiding the interviewee about the characteristics of the product or service [13]. Stimuli are developed, i.e. themes that will be used to carry out interviews. These themes are intended to give the interviewers an indicative framework, as well as to awaken the interviewee's thoughts on the subject of the interview. The themes used in this study were based on literature $[34,35]$. Four themes were applied in study: 1) communication status; 2) message content; 3) application features; and 4) my theme.

The first theme examines how the communication situation and the target, as well as the factors associated with them, affect what the message application the interviewee decides to use. The second theme deals with factors related to the content of the message and its effects on message application selection. The third theme focuses on the features of the message application itself and on how the features of the messaging application affect the choice of the message application. A fourth theme was used for some factors that not sit on any of those three ready-made themes. 


\subsection{Data Collection}

We interviewed 25 participants from a university in Finland. The average age was 22 years with most of the interviewees being 24-26 years old (86\%) which were $56 \%$ men, $40 \%$ women, and $4 \%$ (i.e. one person) preferred not to report the gender. $60 \%$ of the participants reported to be working while the remaining $40 \%$ were full time students. This follows what is common for business and information technology university students in Finland.

The interviewer went through the themes one at a time and started by asking "How do things related to this theme affect what message application you are going to use?" On average, the interviewees came up with about 4-5 ideas per theme. Next, each of the ideas were explored with further questions, so that the value chain behind each case was captured in its entirety. The interviewees were then asked, for example, "Why does this matter affect the choice of your messaging application?" Or "Why do you consider this matter important?" These questions were repeated until a complete value chain with feature, consequence, and value was recorded for each subject's message. If the interviewee's value chains branched, for example if the interviewee identified two consequences for a property, then both of these consequences were considered as a separate value chain and the underlying value was determined separately for both chains. When analysing the material, such branched chains were stored in their own chain. After the first theme was passed through with the interviewee, the same process was repeated with another theme. Figure 1 illustrates a sample thematic map.

\subsection{Data Analysis}

The data analysis was carried out following the thematic qualitative clustering approach presented by Tuunanen and Peffers [14]. This approach fits well for studies with 20-30 interviewees [14]. The purpose of the model is first to combine the material into a single entity, after which it is clustered and cut into smaller entities. Based on these smaller entities, the material can be divided into different themes into which the collected value chains can be divided. The data collected from this theme can be presented in graphical form using value or theme maps. These maps consist of value chains shown by the interviewees, with features on the left side of the map, consequences in the middle, and values on the right [15]. Within each theme, efforts were made to find connecting factors from the properties of the value chains, from the consequences and from the values. This allowed the value chains in each theme to be divided into such a form that it would be possible to draw a graphic thematic map. The numbers for each map items

Figure 1. Nature of Communication

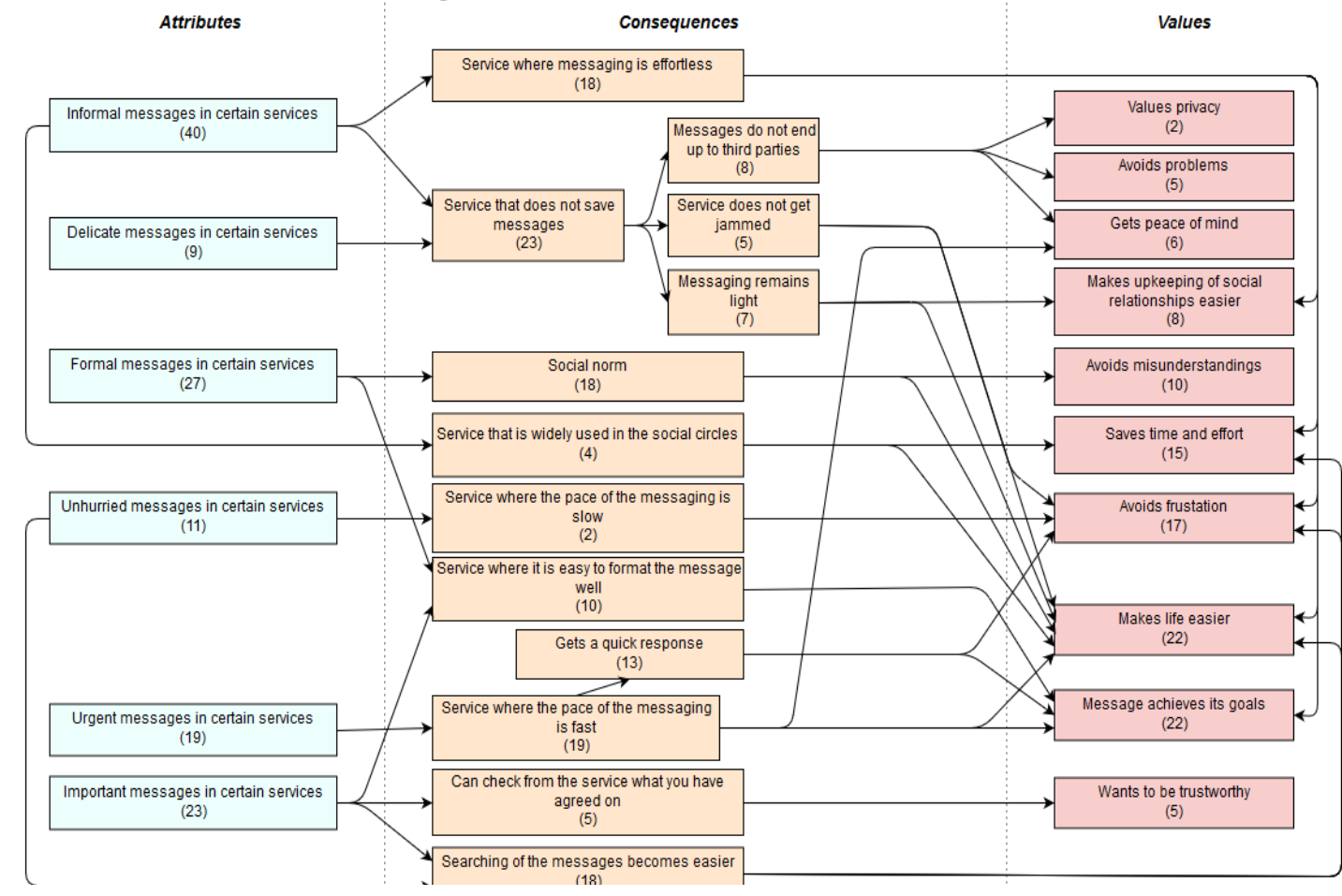


tell how many times these were mentioned in the data set for a specific thematic map.

\section{Findings}

\subsection{Context of Communication}

The first theme comprises of value chains that correspond to the way the time and place of communication and whether the work or leisure time message affects the choice of the message application. A total of 21 value chains of the study were classified as part of this theme.

Features: Interviewees reported that they communicate work-related messages with specific applications and, in turn, free-time messages with certain applications. They also reported that the time of communication may affect application selection. In addition, it was important for application selection if communication takes place in a place where there is no Internet connection. Most of the features of this theme in interviews were raised by the fact that work-related messages are sent in specific applications.

Consequences: The interviewees presented the consequence of the value chain characteristics described above, that they limit the work messages to specific applications, as these applications support work and work-related communication. By limiting the use of applications in this way, the risk of sending work messages to the wrong people is also reduced. They said that focusing on workflows for specific applications would not focus on leisure messages during working hours, which in turn would improve concentration. By restricting work and leisure messages to specific applications, they find it easier not to think about workrelated messages in their free time. Interviewees said they preferred applications that they thought were well suited for leisure time communication. The time of communication was in turn influenced by application selection, as people are available in different applications at different times of the day. If communication takes place where there is no Internet connection, then it results in an application that can communicate without an Internet connection. You can then send the message you want.

Values: Values such as saving time and effort, improving the quality and efficiency of work, making life easier, and avoiding frustration were reported. There is also a desire to avoid frustration. Also, the interviewees do not want their work tools to end up in the hands of false people to avoid problems. According to the interviewees, the fact that work messages are not kept in free time, in turn, promotes mental well-being and coping. Sending free-time messages suitable for leisure communication is perceived by the interviewees as facilitating life. Because people can be accessed at different times in different applications, the interviewees feel that application selection matters so that the message reaches its goals better. The final value in this theme is the achievement of peace of mind, which is also behind the fact that the selected application sends a message without an Internet connection.

\subsection{Nature of Communication}

The second theme includes value chains related to the way in which the sensitivity, urgency, importance, and officiality of a message affects the choice of a messaging application. A total of 129 value chains were included in this theme. This theme contains the most value chains of the four themes of this study.

Features: In this theme, the characteristics of value chains are related to the nature of the message. The nature of the message refers to whether it is a sensitive message, an important message, an everyday or official message, or an urgent or urgent message. Interviewees report that application selection is affected by the nature of the message and that certain messages are sent in specific applications. In terms of the features of this theme, many references to interviews were given by the features that influence the choice of application in terms of the message's timeliness, formality, urgency, and importance.

Consequences: Interviewees reported that certain applications are easy and convenient to communicate and because the selected application is widely used in their own social circles. In addition, they reported that everyday messages are being sent in applications that $d o$ not store messages. Interviewees also reported that sensitive messages are also sent with an application that does not store messages. An application that does not store messages is selected to send sensitive messages to interviewees because the messages do not end up in a third party. Instead, in the case of everyday messages, the messages do not want to be recorded because, firstly, the communication stays light, and secondly, the application does not get congested from the stored messages.

The interviewees also report official messages in some specific applications, mainly because of social norms, but also because it is easy to design the message in the chosen application. The interviewees reported that, in certain applications, communications are not so hectic and fast, and because, when you know which application can find unexplored messages, it is easier to find messages. Instead, the interviewees reported urgent messages in applications where communication is fastpaced. The interviewees reported about sending important messages in specific applications because in these applications it is easy to format the messages well. 
Sending important messages in specific applications makes it easier to search for messages, as well as checking things out of the application afterwards. In terms of the implications of this theme, many of the consequences were often raised in the interviews.

Values: Interviewees reported that an application with easy and effortless messages is chosen for the reason that it facilitates the maintenance of social relationships, saves time and effort, facilitates life, helps the message reach its goals, and reduces the feeling of frustration. Interviewees do not want their messages to end up with third parties, because they firstly value their privacy. Secondly, they want to avoid problems, and thirdly they want to get peace of mind. They also said that when the application is not overloaded with messages, it avoids frustration and makes life easier.

According to the interviewees, communication should be light, because in this case life and especially the maintenance of social relations is facilitated. According to the social norm, the interviewees said they were working, because even then life would be easier and misunderstandings diminished. The application, which is widely used in its own social circles, is chosen by the interviewees for the reason that such activity saves time and effort and makes life easier. Instead, an application that makes it easy to formulate a message is chosen by the interviewees because the message reaches its goals better.

An application where communication is not fastpaced is chosen by the interviewees because they are able to avoid the feeling of frustration. Instead, an application where communication is fast-paced is chosen by the interviewees because then the message reaches its goals better, the message gets faster, or in order to achieve peace of mind. Interviewees said they wanted a response quickly either because the message reached its goals, or because they could avoid the feeling of frustration. The ease with which the people searched for the messages was appreciated by the interviewees because it made life easier, save time and effort, and lessen the feeling of frustration.

\subsection{Message Subject}

The third theme, comprises value chains related to the manner in which the message's age, authority and number, and whether the recipient is a known or unknown person, influences the choice of the message application. A total of 65 value chains were included in this theme.

Features: The features of this theme, that is, things that affect the choice of the message application and are related to the subject of the message, or the age of the recipient of the message. Also important is whether the recipient is already familiar or an unknown person, whether the subject of the message is for an official entity, or whether more than one person is the subject of the message.

Consequences: The age of the recipient of the message affects the choice of the messaging application because people of different ages know how to use different applications. If the subject of the message is an unfamiliar person, the interviewees report that a specific application can be selected first because the unknowns only want to communicate in specific applications, which in turn can result in a better response to the messages of close people when knowing which application contains what messages.

When communicating to an unknown person, a specific application may be chosen because it is easy to approach unknown persons or because the communication is natural in the chosen application. When communicating to unknown persons, a specific application can also be chosen because it is a social norm to communicate to unknowns with certain applications. If the subject of the message is a familiar person, the application selection is also influenced by the fact that communication is natural in the selected application, or that application selection is a social norm. When communicating to a person you know, a specific application can also be chosen for the reason that the application is widely used in its own social circles.

When the subject of the message is an official body, a specific application can be selected first because the contact details communicated by official authorities direct them to certain applications. Even in this case, if the subject of the message is an official body, the choice of application may be influenced by the fact that it is a social norm to communicate to official bodies with specific applications. If the subject of the message is more than one person, an application is chosen where it is easy to send the same message to many people.

Values: Interviewees said they wanted to communicate to unknowns in specific applications because they appreciate their privacy, and because they only communicate in certain applications to strangers, so they can respond better to the messages of close people, which in turn facilitates the maintenance of social relationships. An application where it is easy to approach unknowns is chosen because, first of all, by doing so, the message better achieves its objectives, secondly, avoids misunderstandings and thirdly, communicating with such an application facilitates life.

The application, where communication feels natural, is also chosen by the interviewees for the reason that the message achieves its goals better, or that the activity saves time and effort. Communicating through an application where communication is natural also reduces misunderstanding. The application, which is 
widely used in its own social circles, is chosen because, in this way, working in the first place saves time and effort and facilitates the maintenance of social relationships.

According to the interviewees, the fact that the contact details of the message item are easily found in an application makes life easier, and saves time and effort. Also, an application that makes it easy to send the same message to many people is chosen to make it easier for you to maintain social relationships, make life easier, save time and effort, and help your message achieve its goals better. According to the social norm, the interviewees report that they work in turn because they want to avoid misunderstandings. According to the interviewees, the fact that life is easier may, in turn, lead to a lesser feeling of frustration.

\subsection{Message Content}

The fourth theme, the content of the message, contains value chains that correspond to how the message is in text, image, video, or audio format, and whether the content of the message is ready in the application affects the choice of the message application. A total of 64 value chains were included in this theme.

Characteristics: The value chain properties associated with message content and content format are, related to the form in which the message is sent, and to the content that is already being sent in an application. Interviewees reported that they send picture messages, voice messages, or text based messages with specific applications. They also reported that it affects application choice, whether it is a long or short textbased message. They reported that application selection is often done based on the content of the message and the format of the content. Some of the interviewees said that if the content they are posting is already in an application, then they will send that content in the same application.

Consequences: Interviewees reported that they post picture and video messages in specific applications, as these applications automatically store the images. Thus, the old content can be returned to later. When sending picture and video messages, application selection may also be affected by quality of the content. If the message contains attachments or a voice message, the selection of application is made if the application is considered suitable for sending the content. When sending long text-based messages, the choice of application may be influenced by the social norm by which they work. In the case of text-based messages and especially short text-based messages, application selection can be affected by the fact that selecting a particular application speeds up communication. Application selection is because certain types of applications are suitable for a certain type of communication, and in this case it is easier to convey their own feelings to the recipient of the message. Application choice is made according to the content of the message, also social norms, and because there is no need to vary so much between different applications. When considering the content of the message and the form of the content, the application selection can also be the result simply because the selected application is suitable for sending the desired messages and contents. This, in turn, can, according to interviewees, lead to an application being more comfortable.

Values: Interviewees said that it is preferable that the application is more comfortable to use, and can store old photos. For the same reason, the interviewees also wanted their content to remain in good quality in the chosen application. The interviewees also report that it will be a good idea for them to be able to convey their feelings better to the recipient of the message. When the message is able to better express their own feelings to the recipient of the message, misunderstandings are reduced. By acting according to the social norm, they can avoid misunderstandings and make life easier. The fact that there is no need to vary between different applications saves time and effort. The speed of communication also saves time and effort but also helps the message reach its goals. The fact that the application is suitable for sending messages and content of any kind to facilitate life, save time and effort, help the message reach its goals, and reduce misunderstandings.

\subsection{Message Application Features}

The final theme comprises of value chains that correspond to the way in which the message application properties, as well as factors associated with these features, affect the choice of the message application. A total of 47 value chains of the study were classified as part of this theme.

Features: The features of the messaging application and the factors associated with these features mean that the choice of a messaging application is first and foremost due to the ease of use of the application. Also, if the application works smoothly, and does not contain bugs affects the choice of the message application. If the application works well with other applications it may affect the choice of the message application. The interviewees also reported that they are trying to communicate with applications that are used by many others. Also, if the application can handle a wide range of communications and send a wide variety of content may influence the choice of the message application. If the recipient of the message ready in some application, this will also guide their application selection to a 
specific application. If it is easy to find messages in the application or if the application is visually pleasing, this can be the basis of application selection. Also, if you see from the application whether the message has been sent, you can redirect it to a specific application. According to the interviewees, the fact that the application encrypts messages, as well as the fact that there are no security issues in the application, can affect their application choice. The interviewees reported that it might also affect the choice of their messaging application, whether the application is free of charge.

Consequences: Interviewees reported that when the selected application works well with other applications, has no bugs, and is easy to use, the application will become smoother. The interviewees try to communicate with applications they use a lot, and if that application can handle a wide range of communications and send a wide variety of content, they do not have to vary so much between different applications. The fact that the contact information of the recipient of the message is already in some application facilitates and speeds up communication. If it is easy to find messages in the application then this makes it easier to review the agreed things from the application afterwards. If the application is visually pleasing then the application will become more enjoyable. If the application can display if the message has reached its destination, the interviewees say this will make it easier to follow the message. An application that encrypts messages, and otherwise does not contain security issues, is chosen by the interviewees because the messages are not likely to end up in third parties. If communication with the application is free of charge, then naturally sending messages does not cause extra costs.

Values: The smoother use of the application leads the interviewees feeling good or the use of the application does not burden the user. The smooth running of the application also saves time and effort and helps to avoid frustration. The fact that users do not have to vary between different applications also helps to avoid the feeling of frustration, but also makes life easier, and saves time and effort. With the ease and speed of communication, there are the same three above-mentioned values in the background. Facilitating and accelerating communication saves time and effort, makes life easier and reduces the feeling of frustration and also helps them to be more reliable. If it is possible to follow the application to see if the message is sent it gives peace of mind. Interviewees do not want their messages to end up with third parties because they value their privacy. When messages do not end up with third parties also gives peace of mind and helps them avoid problems.

\section{Discussion}

The findings of this study show that the choice of message applications across the board is influenced by which application choice saves the consumer's time and effort and makes his or her life easier. Similar results were obtained by Chang, et al. [23] when examining factors affecting consumer behaviour of mobile purchasing. According to them, the consumer's decision whether to buy products is influenced, among other things, by the way in which each consumer perceives it as the easiest.

The findings of this paper show that there are numerous reasons why consumers feel the choice to save their time and effort and make their lives easier. One may wonder how many of the factors influencing the switching behaviour of digital services are precisely the fact that consumers are trying to save their time and effort and to make life easier in a certain way. For example, there is good reason to assume that when Hsieh, et al. [10] suggest that the consumer switch from one blog service to another because he or she feels easier to use another service over the other, there are the same values and goals, namely saving time and effort and life making it easier for the consumer. Thus, it can be suggested that consumer switching behaviour in the context of digital services, and in particular mobile services, is strongly driven by two factors in particular: saving time and effort and making life easier.

However, it is worth pointing out that, although consumers today have the opportunity to satisfy a single need in many services, such as sending messages with many different messaging applications, this does not mean that unlimited freedom of choice between different services would only be a positive thing for consumers. The results of this study show that the constant variation between applications can cause a feeling of frustration, as a result of which the consumer tries to avoid constant variation between different applications. Although consumers nowadays have a very good chance to vary between different messaging applications, constant variation between different services or applications may seem frustrating to the consumer.

The PPM framework explains the most frequently exchanged behaviour in exchange behaviour studies in the context of information systems [16]. The factors that explain switching behaviour are either push factors, i.e. factors that push the consumer away from the current product or service. Such as driving factors that pull the consumer into another alternative product or service or mooring factors that indirectly affect these pushing or pulling factors, but rarely in themselves, cause exchange behaviour [1]. 
Bansal, et al. [1] suggest that when speaking about services in general, the most frequent push factors that cause switching behaviour are the poor quality of the current service, the inadequate value of the current service, the current service low confidence in the current service, poor commitment to the current service, and high cost of the current service. In the context of digital services, the poor quality of the current service [24], general dissatisfaction with the current service [11,25], as well as the lack of enjoyment provided by the current service [26, 27] are common pushing factors.

Instead, when talking about pulling factors in the context of services, Bansal, et al. [1] suggest that these factors are most commonly associated with the attractiveness of an alternative service. Also, in the context of digital services, the attractiveness of alternative services $[6,24]$ is a generic driving factor that causes interchange behaviour. Another common pulling factor in the context of digital services is the ease of use of an alternative service [10,28]. According to the results of this study, when talking about smart phone apps, the pull factors are that the application fits into the context of communication, the application for sending the desired content and that it has a good level of functionality and usability.

According to Bansal, et al. [1], the mooring factors are, in the context of services, among other things, the negative attitude towards the exchange of services, the high exchange costs caused by the exchange, the limited experience of the exchange of services, and subjective norms. Also in the context of digital services, general mooring factors that affect switching behaviour are exchange costs $[29,30]$, past experiences of service exchange [10,24], habits and habits [31], as well as subjective norms [28]. According to our findings, when talking about messaging applications used on smart phone devices, the mooring factors are, in turn, a negative attitude towards continuous variation between applications, and social norms that can guide application selection in a particular direction.

The findings of this paper show that the application of the PPM framework in situations such as this one where consumers use multiple services or applications simultaneously or almost simultaneously can be challenging. It is natural for the factors that explain the behaviour of the switcher to be categorized according to the PPM framework in situations where the consumer is initially a customer of a single service provider or product manufacturer, whom he or she will then become a customer of another service provider or product manufacturer. That is, stop using the old product or service and replace it with a new one. On the other hand, in situations such as this, where the consumer uses a number of services to satisfy one need, and therefore does not completely switch from one service to another, but chooses the service that is best suited to each situation, the breakdown of the factors explaining the switching behaviour according to the PPM framework is challenging.

The fact that the use of the PPM framework in such situations is challenging is evident, among other things. As can be seen from table 1, the pushing and pulling factors are almost identical and differ only in that the pushing factors look at why one of the messaging applications is switched off and the pulling factors, in turn, cause the switching to a particular application. However, the content of these reasons explaining the exchange is completely the same. This is because in situations like this one, it is challenging to determine whether the factor causing the change of behaviour is pushing or pulling. For example, whether an application does not fit or fits in the context of the communication or the transmission of the desired content, is in principle, a push or pull factor.

Table 1. Main results of the study broken down by the PPM framework

\begin{tabular}{|l|l|l|l|}
\hline Source & Push Factors & Pull Factors & Mooring Factors \\
\hline $\begin{array}{l}\text { Bansal } \\
\text { et al. }\end{array}\left[\begin{array}{l}\text { Poor quality of current service } \\
\text { The invalid value provided by the } \\
\text { current service } \\
\text { Low confidence in current } \\
\text { service } \\
\text { Weak commitment to current } \\
\text { service } \\
\text { The high cost of existing service }\end{array}\right.$ & $\begin{array}{l}\text { The attractiveness of } \\
\text { Alternative Service }\end{array}$ & $\begin{array}{l}\text { Negative attitude to service } \\
\text { exchange } \\
\text { High exchange costs due to } \\
\text { exchange } \\
\text { Little experience in changing } \\
\text { services } \\
\text { Subjective norms }\end{array}$ \\
\hline $\begin{array}{l}\text { This } \\
\text { study }\end{array}$ & $\begin{array}{l}\text { Application is not compatible } \\
\text { with the communication context } \\
\text { Application is not suitable for } \\
\text { sending the desired content } \\
\text { The application is not satisfactory } \\
\text { in terms of functionality and } \\
\text { usability }\end{array}$ & $\begin{array}{l}\text { Application suitable for } \\
\text { communication context } \\
\text { The app is suitable for } \\
\text { sending the desired content } \\
\text { The application is useful in } \\
\text { functionality and usability }\end{array}$ & $\begin{array}{l}\text { Negative Attitude Between } \\
\text { Continuous Applications for } \\
\text { Variation } \\
\text { Social norms guide application } \\
\text { selection to a specific application }\end{array}$ \\
\hline
\end{tabular}


Bhattacherjee and Park [32] show that it is very challenging to develop a completely theoretical model that is perfectly suited to the research field of consumer exchange behaviour. The PPM framework can be seen as better suited to explaining a change of behaviour in situations where the consumer is first a user of a particular product or service, then something that results in the consumer starting to use an alternative product or service. On the other hand, in situations such as this one, where consumers choose the most appropriate option for a given service from a variety of services, and not switching from one service to another to stop using the old service, the breakdown of the factors that explain the switching behaviour under the PPM framework can be challenging.

\section{Conclusion}

We applied the PPM framework to determine the push factors that influence the decision of the message application. Our theoretical implication was that in situations where consumers choose the most appropriate alternative for a particular use and situation from many services, and not switching from one service to another, stop using the old service, the breakdown of the behavioural factors using the PPM framework can be challenging.

A limitation of this study is that the interviewees were only students from Finland. Further research relates may include age, cultural and socio-economic factors as an impact on the consumer's choice or exchange decision. Hence, it would be interesting to carry out a future study exploring cultural or socioeconomic factors. Future research can also determine is switching is impacted by switching costs.

Finally, we see that it would be highly interesting to extend the scope of the study to other services that mix both mobile and digital, but also physical services such as the Amazon Go shop concept introduced by Amazon recently. In a Amazon Go store a customer experiences a mesh of both physical and digital experience of retail shopping [33] supported by artificial intelligence and different kinds of sensors monitoring the activities of the people inside of the store. If such retail stores become more widely available it will be a "billion-dollar" question to understand the reasons for consumers to switch between seemingly similar, but still different services. We argue that it will be a question of context, content, and features of such service that matter.

\section{References}

[1] H. S. Bansal, S. F. Taylor, and Y. St. James, "'Migrating" to new service providers: Toward a unifying framework of consumers' switching behaviors," Journal of the Academy of Marketing Science, vol. 33, no. 1, pp. 96-115, 2005.

[2] H. S. Bansal and S. F. Taylor, "The service provider switching model (spsm) a model of consumer switching behavior in the services industry," Journal of service Research, vol. 2, no. 2, pp. 200218, 1999.

[3] D. Liang, Z. Ma, and L. Qi, "Service quality and customer switching behavior in China's mobile phone service sector," Journal of Business Research, vol. 66, no. 8, pp. 1161-1167, 2013.

[4] M. Suleiman Awwad and B. Awad Neimat, "Factors affecting switching behavior of mobile service users: The case of Jordan," Journal of Economic and Administrative Sciences, vol. 26, no. 1, pp. 27-51, 2010.

[5] C. Calvo-Porral and J.-P. Lévy-Mangin, "Switching behavior and customer satisfaction in mobile services: Analyzing virtual and traditional operators," Computers in Human Behavior, vol. 49, pp. 532-540, 2015.

[6] I. C. Chang, C. C. Liu, and K. Chen, "The push, pull and mooring effects in virtual migration for social networking sites," Information Systems Journal, vol. 24, no. 4, pp. 323-346, 2014.

[7] Y.-L. Wu, Y.-H. Tao, C.-P. Li, S.-Y. Wang, and C.Y. Chiu, "User-switching behavior in social network sites: A model perspective with drill-down analyses," Computers in Human Behavior, vol. 33, pp. 92-103, 2014.

[8] J.-Y. Lai and J. Wang, "Switching attitudes of Taiwanese middle-aged and elderly patients toward cloud healthcare services: An exploratory study," Technological Forecasting and Social Change, vol. 92, pp. 155-167, 2015.

[9] C. H. Han, S. Tyagi, N. Kim, and B. Choi, "Understanding Internet service switching behaviour based on the stage model," Information Systems and e-Business Management, vol. 14, no. 3, pp. 665-689, 2016.

[10] J.-K. Hsieh, Y.-C. Hsieh, H.-C. Chiu, and Y.-C. Feng, "Post-adoption switching behavior for online service substitutes: A perspective of the push-pullmooring framework," Computers in Human Behavior, vol. 28, no. 5, pp. 1912-1920, 2012.

[11] Y. C. Xu, Y. Yang, Z. Cheng, and J. Lim, "Retaining and attracting users in social networking services: An empirical investigation of cyber migration," The Journal of Strategic Information Systems, vol. 23, no. 3, pp. 239-253, 2014.

[12] K. Peffers, C. E. Gengler, and T. Tuunanen, "Extending critical success factors methodology to facilitate broadly participative information systems planning," Journal of Management Information Systems, vol. 20, no. 1, pp. 51-85, 2003.

[13] T. J. Reynolds and J. Gutman, "Laddering theory, method, analysis, and interpretation," Journal of advertising research, vol. 28, no. 1, pp. 11-31, 1988. T. Tuunanen and K. Peffers, "Population targeted requirements acquisition," European Journal of 
Information Systems, vol. 27, no. 6, pp. 686-711, 2018.

[15] T. Tuunanen, K. Peffers, C. E. Gengler, W. Hui, and V. Virtanen, "Developing feature sets for geographically diverse external end users: a call for value-based preference modeling," Journal of Information Technology Theory and Application (JITTA), vol. 8, no. 2, p. 5, 2006.

[16] J. I. Nykänen, "Synthesis of consumer switching research: A proposal for comprehensive framework," in Teoksessa Selected papers of the Information Systems Research Seminar in Scandinavia (IRIS), 2014, vol. 9, no. 5, pp. 106-120.

[17] E. S. Lee, "A theory of migration," Demography, vol. 3, no. 1, pp. 47-57, 1966.

[18] P. Boyle, K. Halfacree, and V. Robinson, "Exploring contemporary migration Longman," Harlow, United Kingdom, 1998.

[19] B. Moon, "Paradigms in migration research: exploring'moorings' as a schema," Progress in human geography, vol. 19, no. 4, pp. 504-524, 1995.

[20] D. J. Bogue, "Principles of demography," 1969.

[21] Y.-F. Chuang and Y.-F. Tai, "Research on customer switching behavior in the service industry," Management Research Review, vol. 39, no. 8, pp. 925-939, 2016.

[22] T. Tuunanen, M. D. Myers, and H. Cassab, "A conceptual framework for consumer information systems development," Pacific Asia Journal of the Association for Information Systems, vol. 2, no. 1, 2010.

[23] H. H. Chang, K. H. Wong, and S. Y. Li, "Applying push-pull-mooring to investigate channel switching behaviors: M-shopping self-efficacy and switching costs as moderators," Electronic Commerce Research and Applications, vol. 24, pp. 50-67, 2017.

[24] A. C. Hou, C.-C. Chern, H.-G. Chen, and Y.-C. Chen, "'Migrating to a new virtual world': Exploring MMORPG switching through human migration theory," Computers in Human Behavior, vol. 27, no. 5, pp. 1892-1903, 2011.

[25] C. Zengyan, Y. Yinping, and J. Lim, "Cyber migration: An empirical investigation on factors that affect users' switch intentions in social networking sites," in 2009 42nd Hawaii International Conference on System Sciences, 2009: IEEE, pp. 111.
K. Z. Zhang, C. M. Cheung, M. K. Lee, and H. Chen, "Understanding the blog service switching in Hong Kong: an empirical investigation," in Proceedings of the 41st Annual Hawaii International Conference on System Sciences (HICSS 2008), 2008: IEEE, pp. 269-269.

[27] X. Xu, H. Li, J. Heikkilä, and Y. Liu, "Exploring Individuals' Switching Behaviour: An Empirical Investigation in Social Network Games in China," in Bled eConference, 2013, p. 34.

[28] C. Ye and R. Potter, "The Role of Habit in PostAdoption Switching of Personal Information Technologies: An Empirical Investigation," CAIS, vol. 28 , p. $35,2011$.

[29] H.-C. Chiu, Y.-C. Hsieh, J. Roan, K.-J. Tseng, and J.-K. Hsieh, "The challenge for multichannel services: Cross-channel free-riding behavior," Electronic Commerce Research and Applications, vol. 10, no. 2, pp. 268-277, 2011.

[30] M. Schreiner and T. Hess, "Examining the role of privacy in virtual migration: The case of whatsapp and threema," 2015.

[31] Y. Sun, D. Liu, S. Chen, X. Wu, X.-L. Shen, and X. Zhang, "Understanding users' switching behavior of mobile instant messaging applications: An empirical study from the perspective of push-pull-mooring framework," Computers in Human Behavior, vol. 75, pp. 727-738, 2017.

[32] A. Bhattacherjee and S. C. Park, "Why end-users move to the cloud: a migration-theoretic analysis," European Journal of Information Systems, vol. 23, no. 3, pp. 357-372, 2014.

[33] T. Tuunanen, E. Kazan, M. Salo, R.-L. Leskelä, and S. Gupta, "From digitalization to cybernization : Delivering value with cybernized services," Scandinavian Journal of Information Systems, vol. 31, no. 2, pp. 83-96, 2019.

[34] Y. Kyo and P. Chen, "Selection of mobile valueadded services for system operators using fuzzy synthetic evaluation," Expert Systems With Applications, vol. 30, no, 4, pp. 612-620, 2006.

[35] E. Menichelli and R. Ling, "Modeling relevance of mobile communication services by social setting dimensions," New Media \& Society, vol. 20, no. 1, pp. 311-331, 2018. 